\title{
Structural Performance of Reinforced Concrete Beams with Nano- Meta-Kaolin in Shear
}

\author{
Manar A. Ahmed ${ }^{1}$, Ehab M. Lotfy ${ }^{2}$ \\ 1, 2 (Civil Engineering Department, Faculty of Engineering, Suez Canal University, Ismailia, Egypt)
}

\begin{abstract}
The need of high strength and better performance construction materials to keep pace with the rapid development in the construction field elevates researchers to deal with new types of concrete by adding different admixtures to the normal concrete to accomplish desired performance. Meanwhile the researches studying the strength characteristics of such concrete mixes are numerous, the structural performance of casted elements using such new concrete mixes are still under investigation. This research aims to concentrate the shear behavior of Nano-Meta-kaolin-reinforced concrete beams. Different values of shear reinforcement ratio, shear span to depth ratio, and characteristic strength are considered. In perspective of the present research, addition of Nano-Metakaolin, as it basically improves the performance of concrete mixes; it improves the shear performance of reinforced concrete beams; it controls shear cracks and increases shear capacity
\end{abstract}

Keywords: Structural performance, Nano-Meta-kaolin, Shear failure characteristics, stirrups, shear span to depth ratio.

\section{Introduction}

The search for enhancing the concrete STRENGTH and durability as a dominant material in structural applications, despite the trial to reduce the raw materials consumption and environmental hazards that complement with cement manufacturing raised a need of developing concrete with reduced cement content by sensible admixtures addition. Distinctive generally used admixtures, for instance, Meta-kaolin, rice husk ash, fly ash, silica fume, blast furnace slag, are either typically begins, industrial wastes, or by products from industries. Broad investigates have been ran to investigate the effect of Meta-kaolin (MK), as a pozzolanic additive-calcined clay, on the mechanical properties and microstructure of Portland cement mortar $[1,2,5]$, and to identify the optimal percentage of MK to cement content by weight [1, 2, 3,5]. Compressive strength of MK concrete was found to increases around $22 \%$ when compared with normal concrete and fly-ash concrete [4]. The perfect percentage at which cement can be replaced with Nano-Meta-kaolin is 10\%, as communicated in past researches [2].

Some investigations had ran on the structural performance of casted elements using concrete mixes with MK compared to other additives such as fly ash. As regards to shear behavior of beams it is mentioned that MK reinforced concrete beams have higher ultimate loads with lesser deflections than normal and fly ash concrete; the MK-concrete beams average deflection was of $20 \%$ less when compared to normal concrete beams at first crack. In addition, cracks spacing was lesser in MK-concrete compared to fly ash and normal concrete [4].

The usage of MK as an additional substance material as cement portion replacement in concrete matrices proved remarkably enhance compressive strength, toughness, and durability of those matrices compared to the normal concrete. In the meantime, the structure behavior of different elements casted with such concrete is still under investigation. This paper presents an experimental investigation aims at evaluating the shear carrying capacity of Nano-Meta-kaolin reinforced concrete beams in lighting of factors that affect shear characteristic. Seven beam specimens of size $(2000 \mathrm{~mm} \times 100 \mathrm{~mm} \times 200 \mathrm{~mm})$ are tested at 28 days. Nano-Meta-kaolin (NMK) is incorporated as a rate of cement, $10 \%$ as a perfect rate was gotten in perspective of past investigates. The fracture mechanism is studied by focusing on crack and deflection behavior for beams under static loading.

\section{Literature Review}

M. S. Morsy, et al. [3] concentrated the effect of Nano-Clay on mechanical properties and microstructure of ordinary Portland cement mortar; it is verified that the tensile strength of the cement mortars with NMK is higher than that of the plain cement mortar with the same w/b ratio. Deepthi Dennison et al. [5] investigated the effect of Meta-kaolin on the structural behavior of normal and steel fiber reinforced concrete beams, It was mentioned that the mechanical properties of concrete mixes with various replacement percentages of cement by MK increase when the percentage of MK is varied from $0 \%$ to $10 \%$. Beyond $10 \%$ replacement, all the mechanical properties have a 
Structural Performance of Reinforced Concrete Beams with Nano-Meta-Kaolin in Shear

decreasing trend. Aiswarya S. et al. [2] communicated that the perfect rate which cement can be replaced with Metakaolin is 10\%, and the increase of compressive strength varies between 5-38\% for M20 grade and 2-37\% for M30 grade, while the increase of split tensile strength varies between 5-36\% for M20 grade and 2-13\% for M30 grade of concrete. C. N. Sushma et al. [4] performed an experimental study on the shear strength behavior of superplasticized fiber reinforced concrete beams with high reactive Meta-kaolin, it was observed that cracks spacing was lesser in MK-concrete compared to fly ash and normal concrete. Critical exertion has been made in the last few years towards understanding the structural performances of reinforced concrete beams with other additive materials rather than MK; such as fiber reinforced concrete (FRC). The shear carrying capacity of fiber reinforced concrete beams without web reinforcement contains various proportions of glass fibers to the volume of concrete was studied [6], it was observed that optimum improves of compressive strength and shear strength was obtained with $(0.50 \%)$ glass fibers. Liaqat A.Qureshi et al. [7] casted mixes with different percentages of glass fibers by weight of cement, the results showed that compressive strength, flexural strength, and split tensile strength of glass fiber reinforced concrete increase comparing to the control mix. Travis Hockenberry et al. [8] endeavored experimentally to evaluate key factors that affect the shear strength of hooked steel FRC beams with and without stirrups; it was found that the specimens with combinations of fibers and larger stirrup spacing achieved the shear capacity of specimens with no fibers and stirrups at $\mathrm{d} / 2$.

\section{Research Objective}

Researches recently challenge to reduce the environmental hazards caused by construction industry. Among those new attempts is to use green and available supplementary cementitious materials to reduce the negative consequences subsequent to cement manufacture. One of those supplementary on hand is Meta-kaolin. In the last few years, Many studies have bean ran to find out the enhancement in the mechanical properties of the fresh and hardened concrete mix contains MK, and its optimum dosage. However, studies of the structural performance of various reinforced concrete structural elements comprise MK are ongoing. In this research, shear strength characteristics of reinforced concrete beams are investigated experimentally with NMK as a replacement of cement portion in the concrete mix.

\section{Experimental Study}

Seven concrete beam specimens were casted and tested; Nano-Meta-kaolin is added as a percentage of cement, $10 \%$ as an optimum percentage was adopted. The experimental program has been planned to investigate the shear behavior of reinforced concrete beams with NMK under the effect of:

1-Concrete characteristic strength.

2-Shear reinforcement ratio.

3-Shear span to depth ratio.

\section{Cement}

\section{Material Used In Experiment}

The cement utilized during the investigation is 52- grade Ordinary Portland Cement. The cement was purchased from single source. The specific gravity of the above cement was 3.15 and it is conforming to Egyptian Standard Specification [9].

\section{Aggregates}

Natural river sand was used as fine aggregate and broken granite stones of size $20 \mathrm{~mm}$ was used as coarse aggregate. Fine aggregates confirm to Zone II grading with specific gravity 2.64 and bulk density of $1560 \mathrm{~kg} / \mathrm{m}^{3}$ respectively. The specific gravity of coarse aggregate was 2.83 .

3. Water: Clean potable water is used for mixing and curing.

4. Nano-Meta-kaolin: The raw material input in the manufacture of Nano-Meta-kaolin (NMK) is kaolin clay. Kaolin is a fine, white, clay mineral that has been traditionally used in the manufacture of porcelain. Kaolin is also named Chinese-clay. Kaolinite is the mineralogical term that is applicable to kaolin clays. Kaolinite is defined as a common mineral, hydrated aluminum disilicate, $\mathrm{A} 12 \mathrm{Si} 2 \mathrm{O} 5(\mathrm{OH})$. Nano-Meta-kaolin (NMK) is a supplementary cementing material and it is considered as a pozzolanic material, which is without direct cementitious value, but will, in the presence of moisture, reacts chemically with calcium hydroxide $(\mathrm{CH})$ to form compounds possessing cementitious properties. Nano-Meta-kaolin was ground in a heat-treated at $800^{\circ} \mathrm{C}$ for $2 \mathrm{hr}$ high speed ball grinding mill and it was reduced to nano scale, and investigated using SEM Quanta FEG 250 at Suez and Sinai Metallurgical and Materials Research Center of Scientific Excellence (SSMMR-CSE), Suez University, Suez, Egypt. It was observed that the particles sizes were decreased after heat-treatment and the layered were reached to a nano-scale, see figure1-(a,b). 


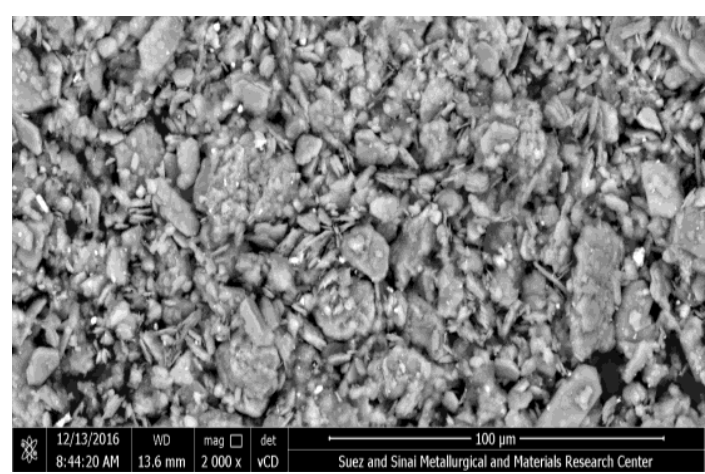

Fig. 1-a: Row Material Meta-kaolin

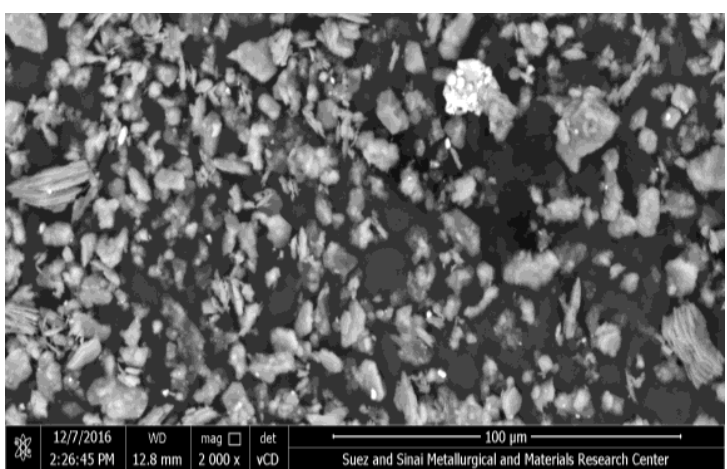

Fig. 1-b: Nano- Meta-kaolin

\section{Specimens Preparation}

The present experimental study involves seven beam specimens of length $2000 \mathrm{~mm}$ with rectangular crosssection of $100 * 200 \mathrm{~mm}$. the longitudinal reinforcement is the same for all specimens; with $2 \Phi 12 \mathrm{~mm}$ as tension reinforcement and $2 \Phi 8 \mathrm{~mm}$ as compression reinforcement. The used stirrups are of $8 \mathrm{~mm}$ diameter with varied distribution to serve the planned experimental program as shown in table 1. The casted beams are divided into three groups as follow:

Group 1: is planned to consider the grade of the NMK-concrete mix in the investigation. Two concrete beams are casted of NMK-concrete mixes of to two different grades, M25 and M35, additional to a control beam casted of normal concrete (without adding NMK). The specimens' details and notations are shown in tables 1 and 2.

Group 2: is assigned to study the effect of replacing $10 \%$ of cement with NMK on shear behavior of concrete beams at different shear reinforcement ratios. The group consists of three beams; beam B2, B4, and B5 with stirrups $5 \varnothing 6 / \mathrm{m}, 10 \varnothing 6 / \mathrm{m}$, and $4 \varnothing 6 /$ beam respectively.

Group 3: targets to study shear behavior for the same concrete mix in group 2 at several shear span to depth ratio $(\mathrm{a} / \mathrm{d})$, this group contains three beams; B2, B6, and B7 with (a/d) equals $3.25,4.5$, and 2 respectively.

Table 1: Specimens details

\begin{tabular}{|c|c|c|c|c|c|}
\hline Beam no. & notation & NMK\% & stirrups & $\mathbf{a} / \mathbf{d}$ & $\mathbf{F}_{\mathbf{c u}}\left(\mathbf{N} / \mathbf{m m}^{\mathbf{2}}\right)$ \\
\hline $\mathrm{B} 1$ & $\mathrm{MK}_{0} \mathrm{~S}_{1} \mathrm{~A}_{1} \mathrm{C}_{1} \mathrm{~B}$ & 0 & $5 \emptyset 6 / \mathrm{m}$ & 3.25 & 25 \\
\hline $\mathrm{B} 2$ & $\mathrm{MK}_{1} \mathrm{~S}_{1} \mathrm{~A}_{1} \mathrm{C}_{1} \mathrm{~B}$ & 10 & $5 \varnothing 6 / \mathrm{m}$ & 3.25 & 25 \\
\hline $\mathrm{B} 3$ & $\mathrm{MK}_{1} \mathrm{~S}_{1} \mathrm{~A}_{1} \mathrm{C}_{2} \mathrm{~B}$ & 10 & $5 \emptyset 6 / \mathrm{m}$ & 3.25 & 35 \\
\hline $\mathrm{B} 4$ & $\mathrm{MK}_{1} \mathrm{~S}_{2} \mathrm{~A}_{1} \mathrm{C}_{1} \mathrm{~B}$ & 10 & $10 \emptyset 6 / \mathrm{m}$ & 3.25 & 25 \\
\hline B5 & $\mathrm{MK}_{1} \mathrm{~S}_{3} \mathrm{~A}_{1} \mathrm{C}_{1} \mathrm{~B}$ & 10 & $4 \varnothing 6 / \mathrm{beam}$ & 3.25 & 25 \\
\hline $\mathrm{B} 6$ & $\mathrm{MK}_{1} \mathrm{~S}_{1} \mathrm{~A}_{2} \mathrm{C}_{1} \mathrm{~B}$ & 10 & $5 \emptyset 6 / \mathrm{m}$ & 4.5 & 25 \\
\hline $\mathrm{B} 7$ & $\mathrm{MK}_{1} \mathrm{~S}_{1} \mathrm{~A}_{3} \mathrm{C}_{1} \mathrm{~B}$ & 10 & $5 \varnothing 6 / \mathrm{m}$ & 2.0 & 25 \\
\hline
\end{tabular}

Table 2: Specimens notations

\begin{tabular}{|c|c|c|c|}
\hline Notation & Implication & Sub notation & Implication \\
\hline \multirow{2}{*}{ NMK } & \multirow{2}{*}{ Nano-Meta-kaolin } & 0 & No NMK added \\
\cline { 3 - 4 } & & 1 & NMK replacement as 10\% of cement \\
\hline \multirow{2}{*}{$\mathrm{S}$} & \multirow{3}{*}{ Stirrups } & 1 & $5 \emptyset 6 / \mathrm{m}$ \\
\cline { 3 - 4 } & & 2 & $10 \emptyset 6 / \mathrm{m}$ \\
\cline { 3 - 4 } & & 3 & $4 \varnothing 6 / \mathrm{beam}$ \\
\hline \multirow{2}{*}{$\mathrm{A}$} & \multirow{3}{*}{ Shear-span to depth ratio (a/d) } & 1 & $\mathrm{a} / \mathrm{d}=3.25$ \\
\cline { 3 - 4 } & & 2 & $\mathrm{a} / \mathrm{d}=4.5$ \\
\cline { 3 - 4 } & & 3 & $\mathrm{a} / \mathrm{d}=2$ \\
\hline \multirow{2}{*}{$\mathrm{C}$} & \multirow{2}{*}{ Concrete grade } & 2 & $\mathrm{M} 25$ \\
\cline { 3 - 4 } & & & $\mathrm{M} 35$ \\
\hline
\end{tabular}

The specimens are cured for 28 days and tested under two point loading applied at $1 / 3$ span points. The beams are tested in Suez Canal research labs, the experimental setup is as shown in figure 2-(a, b). 


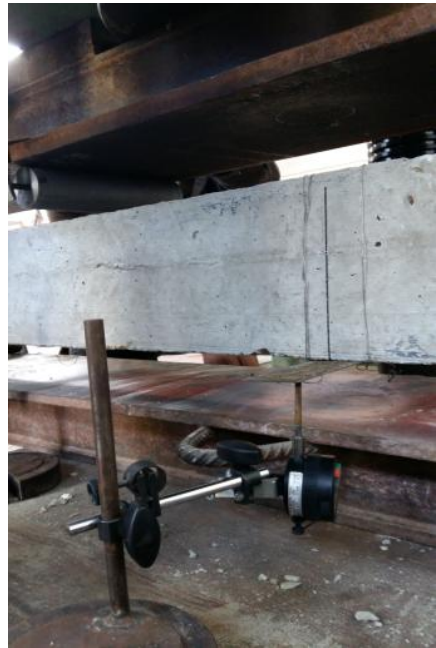

a- Dial gauge is installed to measure deflection.

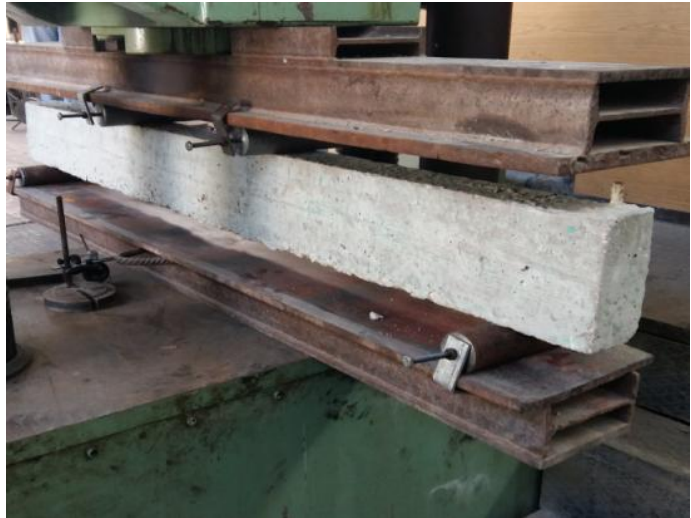

b- Experimental setup - two points loading applied.

Figure 2: Experimental setup.

\section{Results And Discussion}

The structural behavior of the tested reinforced concrete beams is recorded in table 3, the crack pattern for beams B1 to B7 are illustrated on figures 3 to 9 respectively. Type of failure is either shear or flexure-shear as expected for all beam specimens.

Table 3: Experimental results for tested beams

\begin{tabular}{|c|c|c|c|c|c|c|c|}
\hline $\begin{array}{c}\text { Beam } \\
\text { no. }\end{array}$ & $\begin{array}{l}\text { Actual } \mathbf{f}_{\text {cu }} \\
\quad(\mathbf{M p a})\end{array}$ & $\begin{array}{c}\text { First crack } \\
\text { load; } P_{c}(K N)\end{array}$ & $\begin{array}{l}\text { Ultimate } \\
\text { load; } \mathbf{P}_{\mathrm{u}} \\
(\mathrm{KN})\end{array}$ & $\begin{array}{c}\text { Ultimate } \\
\text { deflection; } \delta_{\mathrm{u}} \\
(\mathrm{mm})\end{array}$ & $\begin{array}{c}\text { Max. } \\
\text { deflection; } \delta_{\mathrm{e}} \\
(\mathrm{mm})\end{array}$ & $\begin{array}{c}\text { Toughness } \\
\text { (KN.mm) }\end{array}$ & Type of failure \\
\hline B1 & 27.5 & 19 & 53 & 21.02 & 29 & 1151 & Flexure-shear \\
\hline B2 & 30.5 & 25 & 56.8 & 24.07 & 30 & 1353 & Flexure-shear \\
\hline B3 & 39 & 32 & 62.1 & 22.02 & 32 & 1524 & Shear \\
\hline B4 & 31 & 31 & 60.2 & 20.07 & 32 & 1377 & Flexure-shear \\
\hline B5 & 30 & 9 & 43.3 & 14.49 & 22.5 & 755 & Shear \\
\hline B6 & 31 & 27 & 59.8 & 20.01 & 32.5 & 1568 & Flexure-shear \\
\hline B7 & 30.5 & 18 & 46.3 & 16.04 & 26 & 922 & Shear \\
\hline
\end{tabular}

\section{Specimen group 1 (grade of concrete):}

Normalized load-deflection curves of B1, B2, and B3 are shown on figure 10-a. Beam B2 of concrete grade M25, that strengthened with NMK, exhibits greater load carrying capacity compared to B1, the percentage increase in ultimate load is $7.4 \%$, and the percentage increase in cracking load is $31.5 \%$. In addition, toughness of the NMKstrengthened beam increases by $17.6 \%$. Comparing to beam B2, the percentage increase in cracking load, ultimate load, and toughness value for beam B3 casted of concrete grade M35, and strengthened with NMK are 28\%, 9.3\%, and $12.6 \%$ respectively, see figure 10-(b, c). These results show that improvement in structural performance can be achieved by adding $10 \% \mathrm{NMK}$ as portion of cement to normal concrete rather than upgrading the concrete grade.

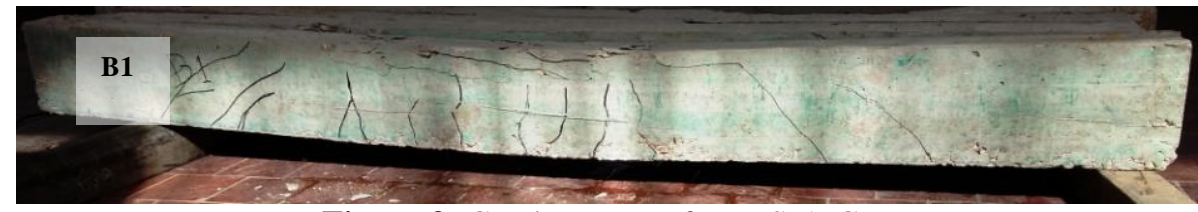

Figure 3: Crack pattern of $\mathrm{MK}_{0} \mathrm{~S}_{1} \mathrm{~A}_{1} \mathrm{C}_{1} \mathrm{~B}$

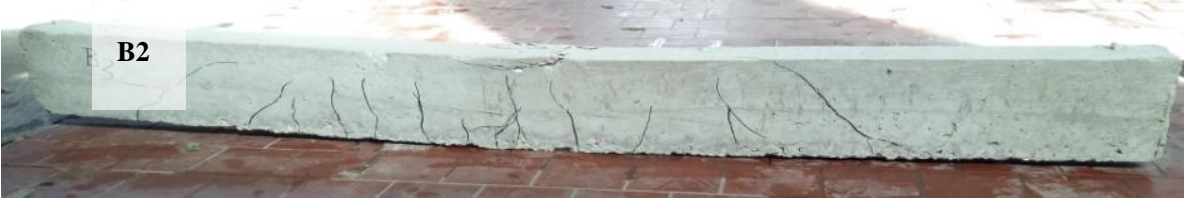

Figure 4: Crack pattern of $\mathrm{MK}_{1} \mathrm{~S}_{1} \mathrm{~A}_{1} \mathrm{C}_{1} \mathrm{~B}$ 


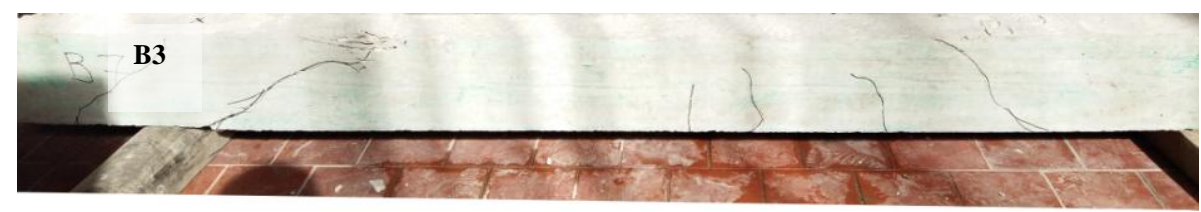

Figure 5: Crack pattern of $\mathrm{MK}_{1} \mathrm{~S}_{1} \mathrm{~A}_{1} \mathrm{C}_{2} \mathrm{~B}$

\section{Specimen group 2 (shear reinforcement ratio):}

The increase in ultimate load is $7.4 \%$ for beam B2 strengthened by NMK compare to B1, on the other side, $5.9 \%$ increase is achieved when shear reinforcement is doubled in B4, as can be noticed from figure 11-a. The superiority of beam results strengthened by NMk on beam with doubled shear reinforcement is observed in cracking load and toughness as well. Cracking load and toughness are enhanced by $31.5 \%$ and $17.6 \%$, respectively for NMKstrengthened beam, compared to $24 \%$ and $1.8 \%$ for doubled shear reinforcement beam, see figure 11-b. Percentage values of B2, B4, and B5 relative to B2 is plotted on figure 11-c to show the effect of different shear reinforcement ratios.

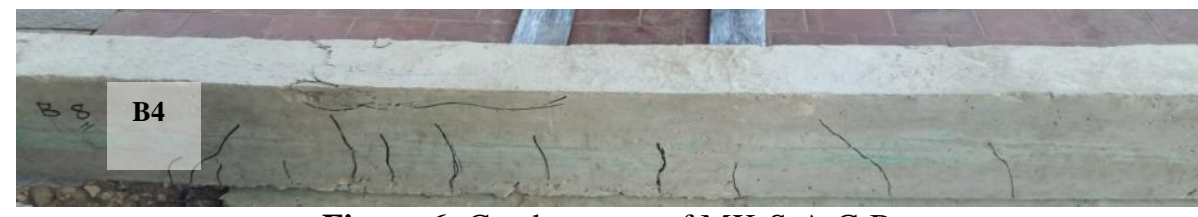

Figure 6: Crack pattern of $\mathrm{MK}_{1} \mathrm{~S}_{2} \mathrm{~A}_{1} \mathrm{C}_{1} \mathrm{~B}$

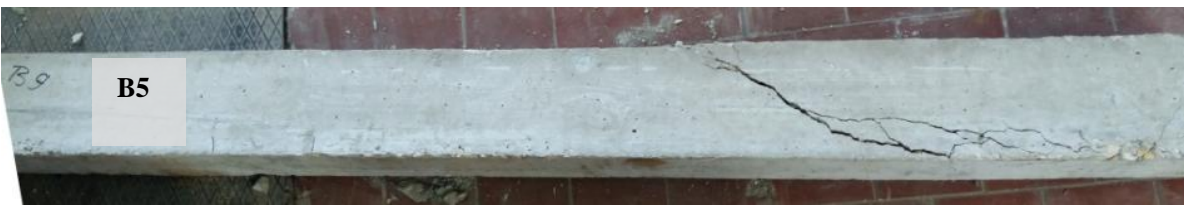

Figure 7: Crack pattern of $\mathrm{MK}_{1} \mathrm{~S}_{3} \mathrm{~A}_{1} \mathrm{C}_{1} \mathrm{~B}$

\section{Specimen group 3 (shear-span to depth ratio):}

By revising crack pattern of the tested beams B2, B6, and B7 with shear-span to depth ratio (a/d) equals 2, 3.25 , and 4.5 respectively, it is observed that strengthening beams by NMK has no significant effect on beam failure mode. Increasing a/d ratio from 2 to 3.25 has substantial effect on the structural behavior as it leads to change the failure mode from shear to flexure-shear mode. Further, cracking load, ultimate load, and toughness increase by $39 \%, 22.7 \%$, and $46.7 \%$ respectively. Increasing a/d ratio from 3.25 to 4.5 has less effect as seen from figure 12-c. The advantage of strengthening beam B2 by NMK over increasing a/d ratio to 4.5 , as in beam B7, on the structural behavior, can be noticed from figure 12-b, especially in first crack load, improvement in ultimate load and toughness is the same for strengthening by NMK or increasing a/d ratio to 4.5 .

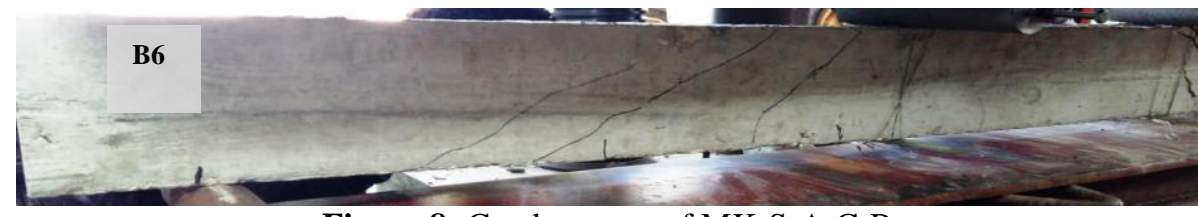

Figure 8: Crack pattern of $\mathrm{MK}_{1} \mathrm{~S}_{1} \mathrm{~A}_{2} \mathrm{C}_{1} \mathrm{~B}$

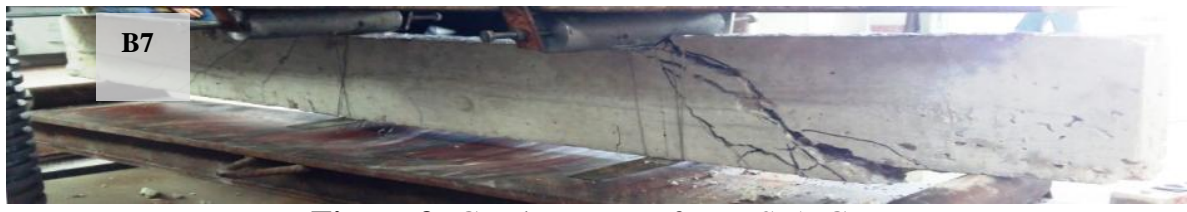

Figure 9: Crack pattern of $\mathrm{MK}_{1} \mathrm{~S}_{1} \mathrm{~A}_{3} \mathrm{C}_{1} \mathrm{~B}$ 


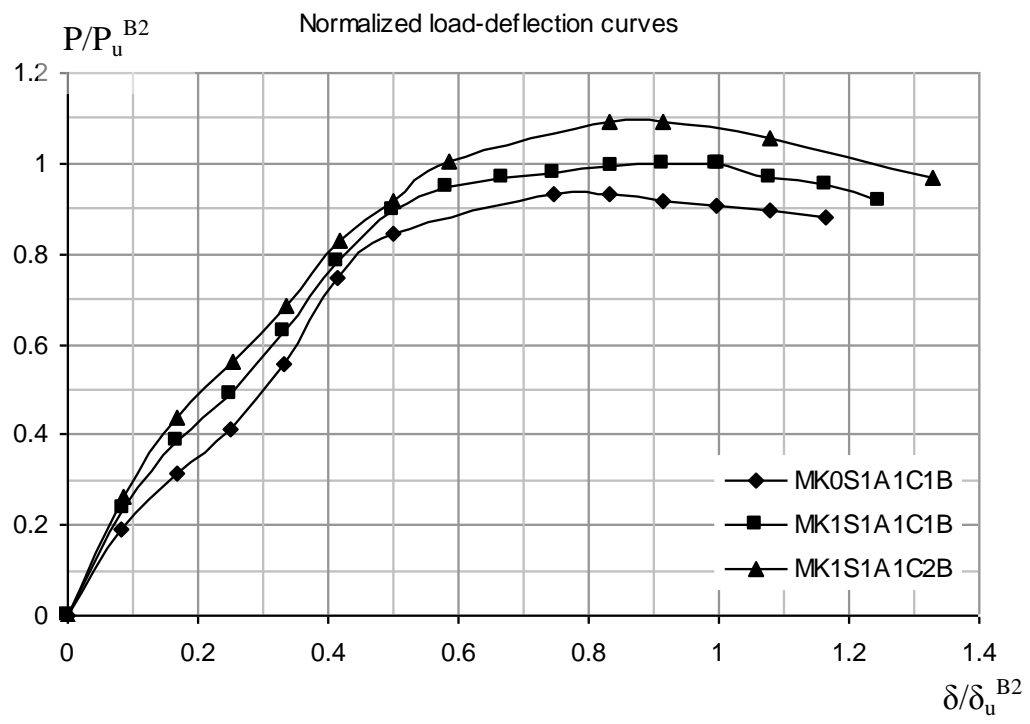

Figure 10-a: Load-deflection curves, effect of NMK compared to different concrete mixes.

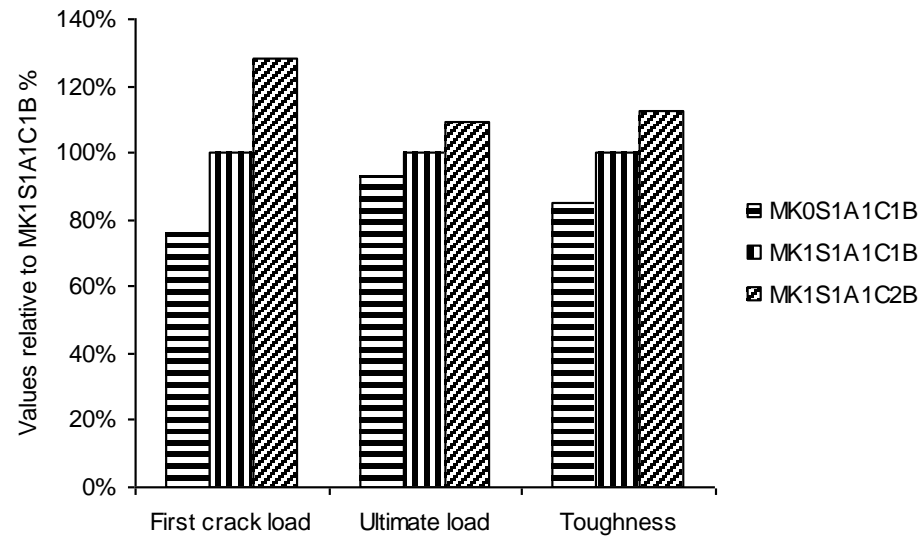

Figure 10-b: Effect of concrete grade on cracking, ultimate load, and toughness-compared to NMK effect.

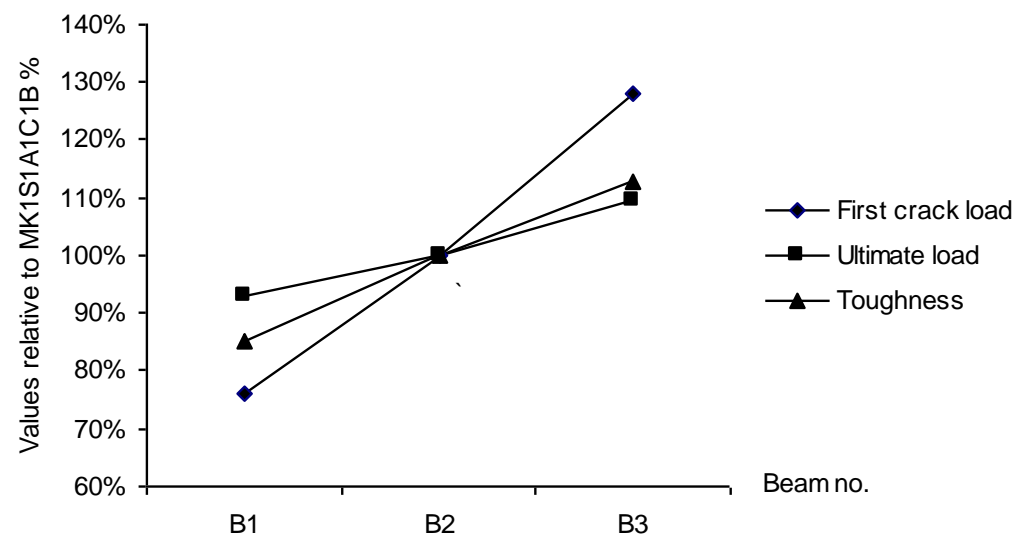

Figure 10-c: Percentage values for $\mathrm{B} 1$ and $\mathrm{B} 3$ relative to $\mathrm{B} 2$. 


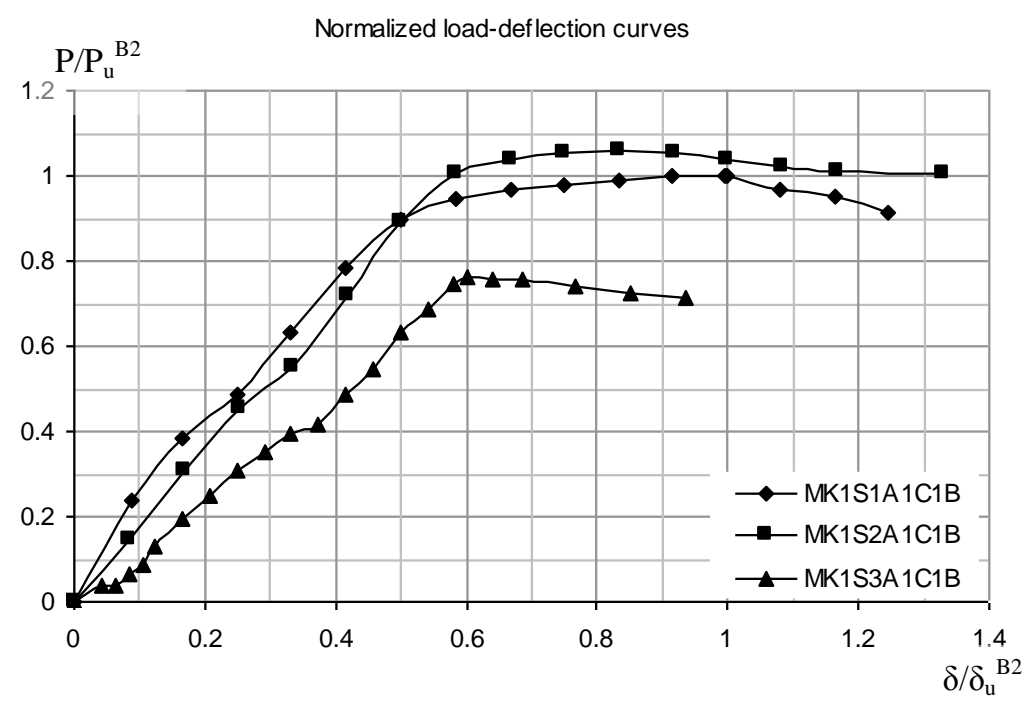

Figure 11-a: Load-deflection curves, effect of shear reinforcement ratio.

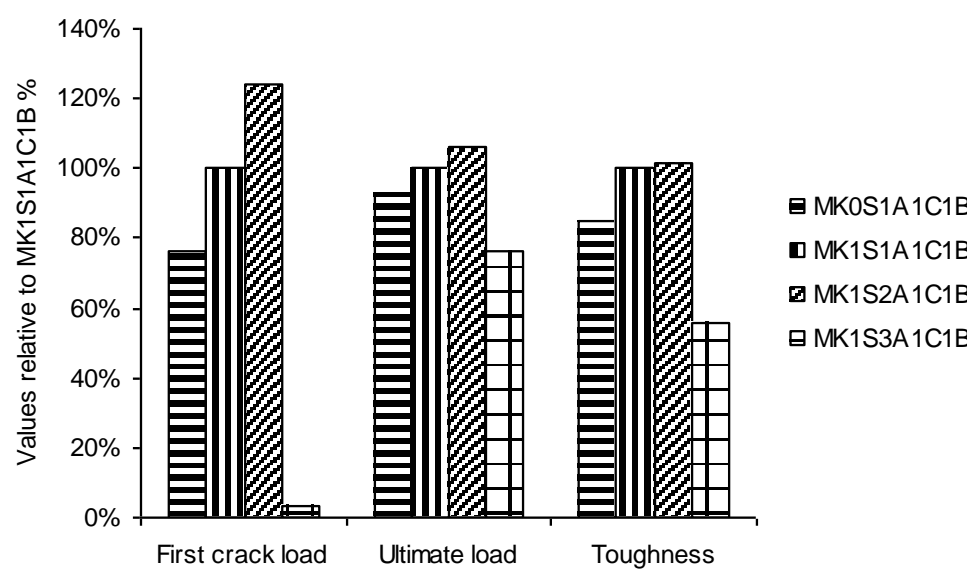

Figure 11-b: Effect of shear reinforcement ratio on cracking, ultimate load, and toughness-compared to NMK effect.

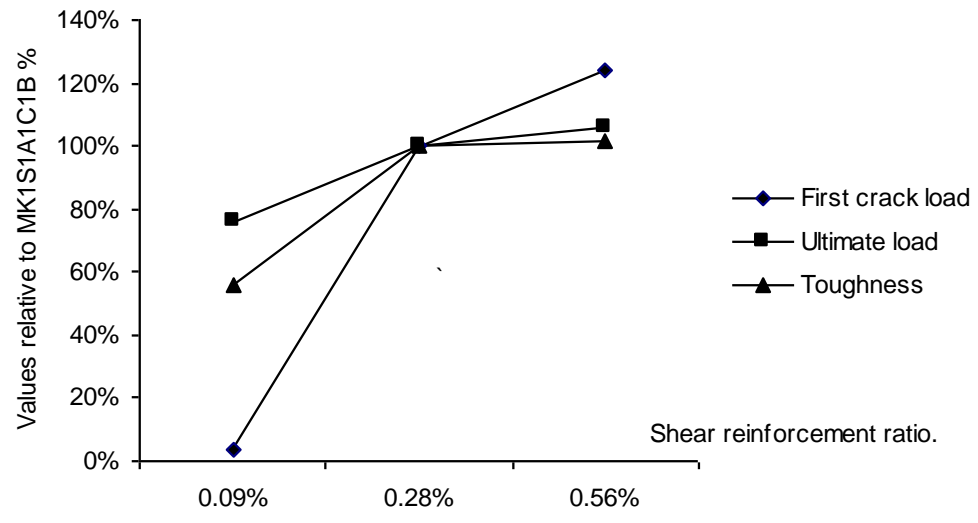

Figure 11-c: Relative percentage values at different shear reinforcement ratios. 


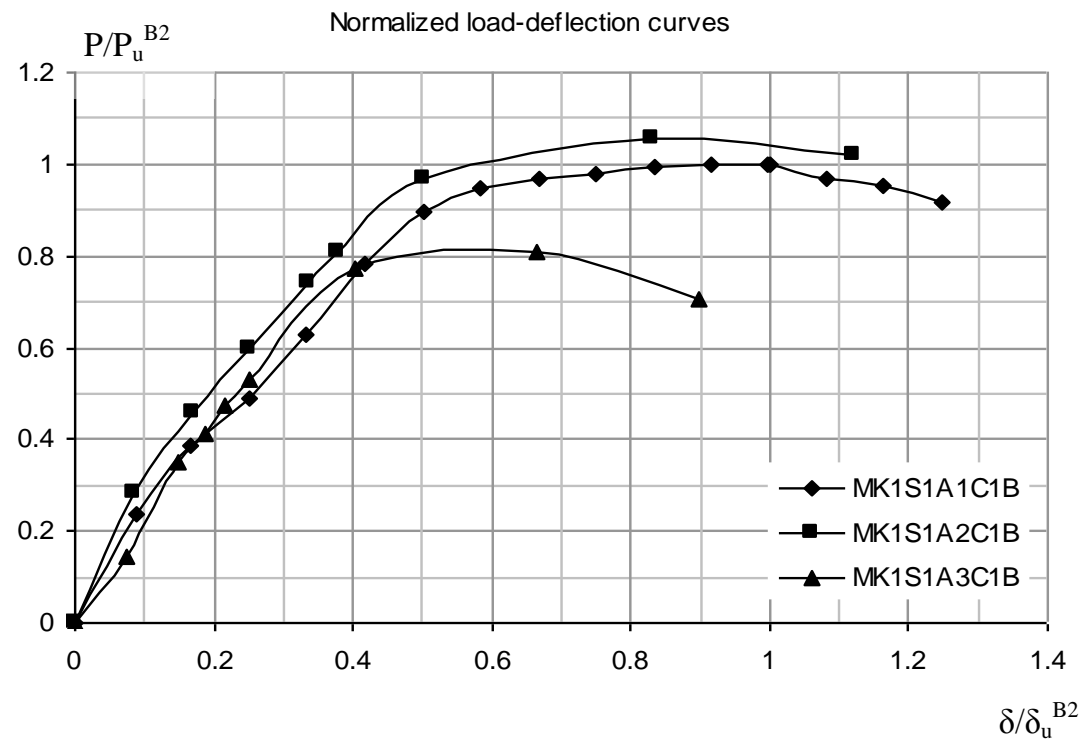

Figure 12-a: Load-deflection curves, effect of shear-span to depth ratio.

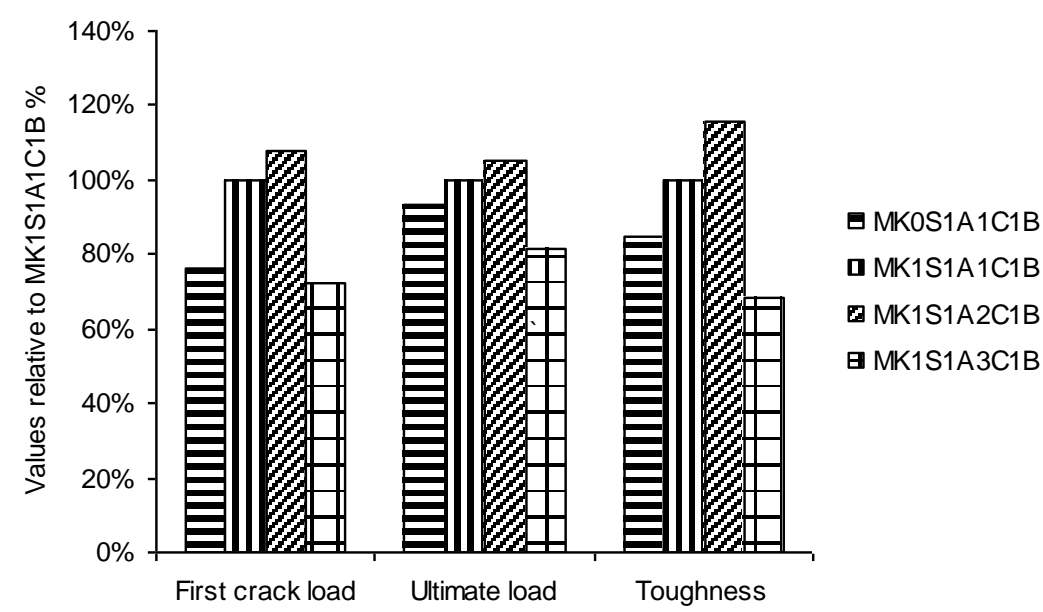

Figure 12-b: Effect of shear-span to depth ratio on cracking, ultimate load, and toughness-compared to NMK effect.

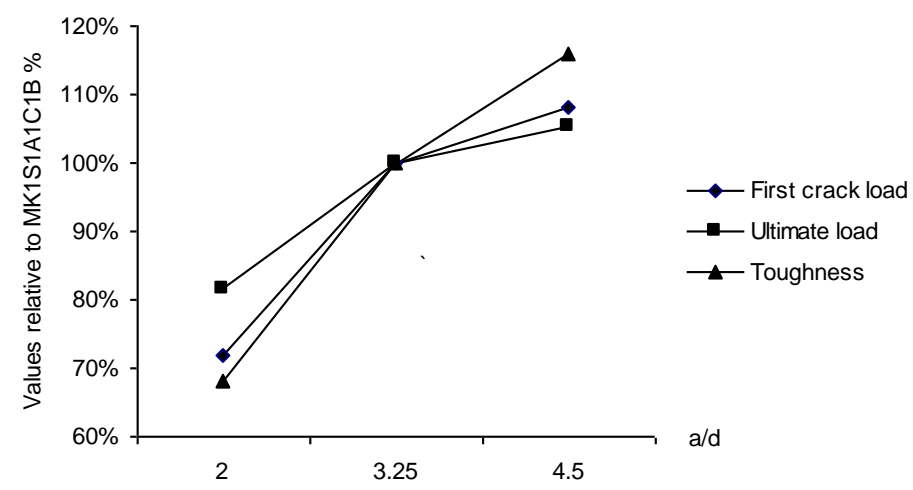

Figure 12-c: Relative percentage values at different shear-span to depth ratios. 
Structural Performance of Reinforced Concrete Beams with Nano-Meta-Kaolin in Shear

\section{Conclusion}

An experimental investigation to understand the shear failure characteristic of Nano-Meta-kaolin reinforced concrete beams is performed considering several values of shear reinforcement ratio, shear-span to depth ratio, and concrete characteristic strength. Seven beams are casted and tested under two points loading, from the results of the experimental study, the following points can be concluded:

1. Ultimate load, cracking load, and toughness of the beam with $10 \%$ NMK as portion of cement increased by $7.4 \%, 31.5 \%$, and $17.6 \%$ respectively compared with normal concrete beam. The percentage increase in ultimate load, cracking load, and toughness value for beam casted of concrete grade M35, and with NMK are $9.3 \%, 28 \%$, and $12.6 \%$, respectively compared to beam casted of concrete grade M25, and with NMK.

2. The improvement achieved in structural behavior by adding NMK to concrete mix of grade M25 is significantly higher than that adding NMK to concrete mix of grade M35.

3. The superiority of beam results with NMK on beam with doubled shear reinforcement is observed, cracking load is enhanced by $31.5 \%$ for beam with NMK compared to normal concrete beam, on the other hand, $24 \%$ increase is achieved when shear reinforcement is doubled. The increase in ultimate load and toughness is $7.4 \%$ and $17.6 \%$, respectively for NMK-concrete beam, compared to $5.9 \%$ and $1.8 \%$ for doubled shear reinforcement beam.

4. Increasing a/d ratio from 2 to 3.25 has substantial effect on the structural behavior as it leads to change the failure mode from shear to flexure-shear mode.

5. Cracking load, ultimate load, and toughness increase by $39 \%, 22.7 \%$, and $46.7 \%$ respectively by increasing a/d ratio from 2 to 3.25 , while increasing a/d ratio from 3.25 to 4.5 has less effect on the structural behavior.

6. Usage concrete with NMK has advantage over increasing a/d ratio from 3.25 to 4.5 regarding the structural behavior enhancement.

7. Usage concrete with NMK has no significant effect on beam failure mode and cracking spacing is lesser in NMK concrete compared to normal concrete.

8. Based on the present research, addition of Nano-Meta-kaolin, as it significantly improves the performance of concrete mixes; it improves the shear performance of reinforced concrete beams; it controls shear cracks and increases shear capacity.

\section{References}

[1]. Amer B. Yusuff "Behaviour of High Strength Reinforced Concrete Beam with Meta-kaolin Under Static Loading", Master thesis, Faculty of Civil Engineering, Universiti Teknologi Malaysia April, 2005.

[2]. Aiswarya S. et al., (2013) "Experimental Investigation on Concrete Containing Nano-Meta-kaolin", IRACST - Engineering Science and Technology: An International Journal (ESTIJ), Vol.3, No.1, and February, 2013.

[3]. M. S. Morsy, et al., (2008) "Effect of Nano-Caly on Mechanical Properties and Microstructure of Ordinary Portland cement Mortar", International Journal of Civil \& Environmental Engineering, Vol. 10, No. 1, pp: 23-27, 2008.

[4]. C. N. Sushma et al., (2016) "Experimental Study on Shear Strength Behavior of Super Plasticized Fiber Reinforced Concrete Beams with High Reactive Meta-kaolin", International Journal of Research in Engineering and Technology, vol. 05, Mar 2016.

[5]. Deepthi Dennison et al., (2014) "Effect of Meta-kaolin on the Structural Behavior of Normal and Steel Fibre Reinforced Concrete Beams", International Journal of Scientific \& Engineering Research, Vol. 5, Issue 7, July 2014.

[6]. Mohd Hashmath et al., (2015) "Experimental Investigation on Strength Characteristics of Shear Strength of Meta-kaolin Blended Glass Fiber Reinforced Concrete", International Journal of Engineering Sciences \& Research Technology Vol. 4, No. 10, October 2015.

[7]. Liaqat A.Qureshi et al., (2013) "An Investigation on Strength Properties of Glass Fiber Reinforced Concrete", International Journal of Scientific and Eng. Research, vol. 2, April 2013.

[8]. Travis Hockenberry et al., (2012) "Performance of Fiber Reinforced Concrete Beams with and without Stirrups", Journal of Civil Environmental and Architectural Engineering, vol. 4, Issue 1, 2012.

[9]. Egyptian Standard Specification, 2002. 